\title{
Resveratrol Regulates Antioxidant Status, Inhibits Cytokine Expression and Restricts Apoptosis in Carbon Tetrachloride Induced Rat Hepatic Injury
}

\author{
Souvik Roy, ${ }^{1}$ Santanu Sannigrahi, ${ }^{1}$ Subhabrota Majumdar, \\ Balaram Ghosh, ${ }^{3}$ and Biswajit Sarkar ${ }^{2}$ \\ ${ }^{1}$ Department of Pharmaceutical Technology, NSHM Knowledge Campus, 124 B.L. Saha Road, Kolkata 700053, India \\ ${ }^{2}$ Department of Pharmacology, Calcutta Institute of Pharmaceutical Technology and AHS, Howrah, Uluberia 711316, India \\ ${ }^{3}$ Department of Pharmacology, Calcutta Medical College, West Bengal, Kolkata 700012, India
}

Correspondence should be addressed to Souvik Roy, souvikroy35@gmail.com

Received 31 May 2011; Revised 6 July 2011; Accepted 7 July 2011

Academic Editor: Ryuichi Morishita

Copyright (C 2011 Souvik Roy et al. This is an open access article distributed under the Creative Commons Attribution License, which permits unrestricted use, distribution, and reproduction in any medium, provided the original work is properly cited.

\begin{abstract}
Recent studies indicate the chemopreventive role of resveratrol in many animal models like ischemia, rheumatoid arthritis, human cancer, and diabetes. The present study was designed to investigate the chemopreventive potential of resveratrol in rat hepatic injury model by carbon tetrachloride. Male Wistar rats were treated with carbon tetrachloride $(0.4 \mathrm{~g} / \mathrm{kg}$ body weight $)$ intraperitoneally daily for 8 weeks. Resveratrol (100 mg/kg, $200 \mathrm{mg} / \mathrm{kg}$ body weight) was given orally from first day until the last day of experiment. The investigation assesses the effect of resveratrol on morphological, oxidative status, histopathological, immunohistochemical, and apoptotic analysis in carbon tetrachloride-challenged liver tissue. The study indicated that the inflammatory cytokines TNF- $\alpha$ and IL-6 were profoundly expressed in experimental rats, whereas resveratrol decreases the immunopositivity of TNF- $\alpha$ and IL- 6 and restored the altered architectural structure of challenged hepatic tissue. Resveratrol also protects liver cells by suppressing oxidative stress and apoptosis.
\end{abstract}

\section{Introduction}

Liver is a major organ responsible for the metabolism of drugs and chemicals and also the primary target organ for many toxic chemicals. The environmental carcinogen, carbon tetrachloride $\left(\mathrm{CCl}_{4}\right)$, has been considered as one of the best characterized experimental model for chemically induced rat liver damage. $\mathrm{CCl}_{4}$ is a classical hepatotoxicant causing liver cirrhosis, fibrosis, and necrosis by producing highly reactive trichloromethyl free radical, initiating lipid peroxidation and causing centrilobular necrosis. High levels of reactive oxygen species (ROS) induce cell damage and are involved in several human pathologies, including liver cirrhosis and fibrosis $[1,2]$. Therefore, the use of compounds with antioxidant properties may prevent or alleviate many diseases associated with ROS. Formation of ROS is a naturally occurring process, and mammalian cells have developed several protective antioxidant defense mechanisms against its formation and detoxification [3]. ROS are also suggested to play an important role in cytochrome $\mathrm{c}$ release from mitochondria followed by apoptotic response. Damaging of kupffer cells, hepatic stellates, and sinusoid endothelial cells resulting in production of pro-inflammatory cytokines like IL-6, TNF- $\alpha$, TGF- $\beta$, eNOS, which are intimately involved in chemical induced hepatotoxic process [4-7] causes infiltration of neutrophiles and monocytes into the damaged organ $[8,9]$. TNF- $\alpha$, IL- 6 are considered as hepatotoxic in several experimental models of liver injuries $[10,11]$.

Resveratrol $\left(3,4^{\prime}, 5\right.$ trihydroxystilbene) is a naturally occurring polyphenol, mainly present in skin of grapes, red wine, mal berries, and peanuts (Figure 1). During the last few years most of the scientific evidence for resveratrol benefits is based on in vivo or in vitro studies in which this compound possesses several pharmacological activities including anticancer [12], antioxidant [13], anti-inflammatory [14], antidiabetic [15], antinociceptive, and antiasthmatic activity [16]. 


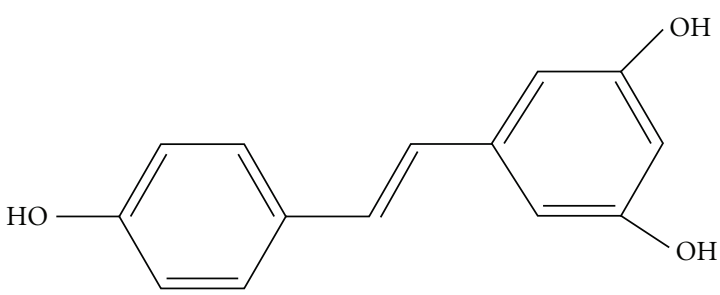

FIgURE 1: Structure of trans resveratrol.

Reports also suggest that it has an effective role in glaucoma [17], pancreatitis [18], and osteoarthritis [19]. It prevents and cures cardiovascular diseases and improves microcirculatory disorders [20]. Resveratrol protects against oxidative stress in cholestasis and exerts hepatoprotective activity against ethanol- and thioacetamide-induced acute and chronic liver damage in rodents $[21,22]$. Resveratrol at low doses decreases ischemia-reperfusion-induced liver injury and protects hepatocytes against antioxidant defense failure [23]. Resveratrol exhibits immunomodulatory effect by suppressing overproduction of inflammatory cytokines like TNF- $\alpha$, IL- $1 \beta$, and IL-6 [24].

Apoptosis is a genetically encoded form of cell suicide central to the development and homeostasis of multicellular organisms $[25,26]$. Previous report suggested that increased hepatocyte apoptosis is an important mechanism contributing to inflammation and fibrogenesis of the liver [1]. There is a growing evidence to suggest that apoptosis is involved in rat liver damage at the early phase in $\mathrm{CCl}_{4}$-induced liver injury [27].

The events that trigger apoptosis in $\mathrm{CCl}_{4}$-induced acute hepatic injury are yet unknown. $\mathrm{CCl}_{4}$-induced toxicity in isolated hepatocytes is mediated by a direct solvent injury to cell membranes [28]. Nonparenchymal cells such as kupffer cells are activated by the release of cytokines, which may contribute to pathophysiological process culminating in hepatocyte apoptosis after toxic injury to the liver [29]. Therefore, we hypothesize that upon $\mathrm{CCl}_{4}$ insult, cytokines are expressed in the liver which alter the apoptotic process and may be reversed by the treatment of resveratrol.

Therefore the present study was undertaken to unveil the possible chemopreventive approach of resveratrol by examining the temporal changes of morphological, histopathological, and TNF- $\alpha$ and IL-6 immunoexpression correlating with the oxidative stress and apoptotic events in $\mathrm{CCl}_{4}$ induced subchronic liver damage of male Wistar rats.

\section{Results}

2.1. Body and Liver Weight. The mean body weights of different groups of rats are shown in Figure 3. No statistical differences were seen between the growth rates of any of the treatment-related groups and control group. A slight decrease of final body weight was observed in $\mathrm{CCl}_{4}$ control group (group B) as compared to normal control (group A), though this result was not statistically significant. Resveratrol-treated groups (group C \& D) maintained the normal body weights compared to normal control (group A), and it suggested that resveratrol had practically no adverse effect on the rat growth response. The mean liver weight along with the relative liver weight of group $\mathrm{B}(P<0.01)$ and group $\mathrm{C}(P<0.05)$ is significant as compared to normal control. Whereas no statistical difference was observed in group D compared to normal control. Furthermore group $\mathrm{D}$ and group A showed significant difference $(P<0.01)$ as compared to $\mathrm{CCl}_{4}$ control (Table 1).

2.2. Effect of Resveratrol on $\mathrm{CCl}_{4}$-Induced Nodular Growth. Visible hepatocyte nodules were not observed in the livers of normal control (group A), whereas macroscopic nodules were clearly seen in the $\mathrm{CCl}_{4}$ control rat liver (Figure 4). Number of rats with nodules, incidence of nodules, total number of nodules, and nodular multiplicity of $\mathrm{CCl}_{4}$ control group along with resveratrol-treated groups were shown in Table 2. A significant $(P<0.05, P<0.01)$ decreased incidence of nodules was observed in resveratrol-treated groups at a dose of $100 \mathrm{mg} / \mathrm{kg}$ (group C) and $200 \mathrm{mg} / \mathrm{kg}$ (group D) as compared to group $\mathrm{B}$; the results were mostly prominent for group D. Likewise the total number of nodules was found to be less in all two resveratrol-treated groups as compared to group B. Nodular multiplicity was found to be significant $(P<0.01)$ in group $\mathrm{C}$ and $\mathrm{D}$ than group $\mathrm{B}$. When a comparison was made between group $\mathrm{C}$ and $\mathrm{D}$, a significance $(P<0.01)$ was emerged for the nodule multiplicity.

Resveratrol treatment at a dose of $100 \mathrm{mg} / \mathrm{kg}$ (group C) and $200 \mathrm{mg} / \mathrm{kg}$ (group D) reduced the appearance of nodules and decreased the development of nodules of less than $3 \mathrm{~mm}$, $1 \mathrm{~mm}$ in size when compared to group B (Table 3). Mean nodular volume was found to be significantly decreased $(P<$ 0.05 ) in group $\mathrm{C}$ as compared to group B. Furthermore, statistically significant results were obtained $(P<0.01)$ in group $\mathrm{D}$ as compared to group $\mathrm{B}$. Nodular volume as a percentage of liver volume was significantly decreased $(P<0.05)$ in group $\mathrm{C}$ in comparison with group $\mathrm{B}$. A significant $(P<$ $0.05, P<0.01)$ decrease in nodular volume as a percentage of liver volume was observed in all resveratrol-treated groups as compared to group B. Group D also showed significant $(P<0.05)$ results when compared to group $\mathrm{C}$.

2.3. Effect of Resveratrol on Lipid Peroxidation, Hepatic GSH and GST. The effects of resveratrol on lipid peroxidation, hepatic GSH, and GST content in liver tissue were shown in Table 4. Malondialdehyde (MDA) is the end product and common marker of lipid peroxidation. The content of MDA was significantly $(P<0.01)$ higher in $\mathrm{CCl}_{4}$ control group. Treatment with resveratrol $100 \mathrm{mg} / \mathrm{kg}$ (group C) and $200 \mathrm{mg} / \mathrm{kg}$ (group D) significantly decreased the MDA content. As the oxidative stress of tissue generally involves the GSH and GST system, we measured the level of GSH and GST in each group of livers. The administration of $\mathrm{CCl}_{4}$ significantly depleted GSH and GST content; treatment with resveratrol significantly protected against the GSH and GST depletion induced by $\mathrm{CCl}_{4}$.

2.4. Effect of Resveratrol on Hepatic Histology. Identification and alteration of histopathological changes during hepatocellular damage and the protective effect of resveratrol 
TABLE 1: Liver weight and relative liver weight of different groups of rats at the end of study (after 8 weeks).

\begin{tabular}{lccc}
\hline Groups & No. of rats & Liver weight $(\mathrm{g})$ & Relative liver weight (g liver/100 g body weight) \\
\hline A & 10 & $10.5 \pm 0.63^{\#}$ & $3.62 \pm 0.45^{\#}$ \\
B & 10 & $13.0 \pm 1.6^{* *}$ & $4.67 \pm 0.7^{* *}$ \\
C & 10 & $12.2 \pm 1.9^{*}$ & $4.51 \pm 0.35^{*}$ \\
D & 10 & $11.0 \pm 1.2^{\#}$ & $3.88 \pm 0.4^{\#}$ \\
\hline
\end{tabular}

Group A, normal control; group B, $\mathrm{CCl}_{4}$ administered rats; group C, resveratrol-(100 mg/kg) treated rats; group D, resveratrol- $(200 \mathrm{mg} / \mathrm{kg})$ treated rats. Results are mean \pm S.E.M for 10 animals; One way ANOVA followed by Dunnett's multiple comparison test.

* indicates value significantly different from the normal control at $P<0.05$.

** indicates value significantly different from the normal control at $P<0.01$.

\# indicates value significantly different from the $\mathrm{CCl}_{4}$ control at $P<0.01$.

TABLE 2: Effect of resveratrol treatment on the development of microscopic hepatocyte nodules induced by $\mathrm{CCl}_{4}$ in $\mathrm{male}_{\mathrm{Wistar}}$ rats.

\begin{tabular}{lcccc}
\hline Groups & $\begin{array}{c}\text { No. of rats with } \\
\text { nodules/total rats }\end{array}$ & Nodule incidence (\%) & Total no. of nodules & $\begin{array}{c}\text { Average no. of nodules/nodule-bearing } \\
\text { liver (nodule multiplicity) }\end{array}$ \\
\hline B & $10 / 10$ & 100 & 246 & $24.6 \pm 2.4$ \\
C & $6 / 10$ & $60^{*}$ & 65 & $10.8 \pm 1.3^{* *}$ \\
D & $3 / 10$ & $30^{* *}$ & 21 & $7 \pm 1.6^{* * \#}$ \\
\hline
\end{tabular}

Group B, $\mathrm{CCl}_{4}$-administered rats; group C, resveratrol- $(100 \mathrm{mg} / \mathrm{kg})$ treated rats; group D, resveratrol- $(200 \mathrm{mg} / \mathrm{kg})$ treated rats.

Results are mean \pm S.E.M for 10 animals; One way ANOVA followed by Dunnett's multiple comparison test.

${ }^{*} P<0.05$ and ${ }^{* *} P<0.01$ as compared with group $\mathrm{B}$.

${ }^{\#} P<0.05$ as compared with group $C$.

Animals from group A did not show visible hepatocyte nodules.

against $\mathrm{CCl}_{4}$-induced toxicity were depicted in Figure 5. Histopathology of liver from the normal control (group A) showed a regular arrangement of hepatocytes with clearly visible nuclei (Figure 5(a)). Intraperitoneal injection of $\mathrm{CCl}_{4}$ at a dose of $0.4 \mathrm{~g} / \mathrm{kg}$ body weight (group B) showed extensive centrilobular necrosis around the central vein of liver and dilation of the central vein with few regenerative areas of hepatocytes around the central vein, and distal part of liver was observed (Figure 5(b)). The magnitude of dilation of the central vein was prominent but very less in group $\mathrm{C}$ as compared with $\mathrm{CCl}_{4}$ control group (group B) (Figure 5(c)). The liver sections from group D showed good protection of hepatocellular necrosis with a poorly dilated central vein and regular arrangement of hepatocytes around the central vein. The distal part of the liver from the central vein was observed along with a scattered regenerative zone of hepatocytes; very few necrotic zones were prominent (Figure 5(d)).

2.5. Effect of Resveratrol on Expression of TNF- $\alpha$. The expression of TNF- $\alpha$ was analyzed by immunohistochemistry (Figure 6), and percentage of TNF- $\alpha$ immunopositive cells in liver tissues of various groups of experimental rats were shown in Table 5. The liver sections of normal control showed complete absence of immunostaining of TNF- $\alpha$ (Figure 6(a)). A large amount of TNF- $\alpha$ immunopositive cells $(28.5 \pm 2.4)$ were detected in the liver tissue sections of the $\mathrm{CCl}_{4}$ control rats (group B) (Figure 6(b)). In contrast, the decrement of TNF- $\alpha$ immunopositivity $(15.3 \pm 3.6),(P<$ $0.05)$ was observed upon resveratrol- $(100 \mathrm{mg} / \mathrm{kg})$ treated rats compared to $\mathrm{CCl}_{4}$ control (Figure 6(c)). Furthermore a more decrement of TNF- $\alpha$ immunopositivity was marked (10.6 \pm $4.7, P<0.01)$ in resveratrol- $(200 \mathrm{mg} / \mathrm{kg})$ treated rats compared to $\mathrm{CCl}_{4}$ control group (Figure 6(d)).
2.6. Effect of Resveratrol on Expression of IL-6. Figure 7 depicted the representative photomicrographs of immunohistochemical staining of IL-6 in liver tissues. Table 5 showed the expression of IL-6 immunopositive cells (as percentage) of various groups of experimental rats. The liver sections of normal control showed complete absence of immunostaining of IL-6 (Figure 7(a)). A large amount of IL-6 immunopositive cells $(18.2 \pm 0.7)$ were detected in the liver tissue sections of the $\mathrm{CCl}_{4}$ control rats (group B) (Figure 7(b)). In contrast, the decrement of IL-6 immunopositivity was observed $(12.4 \pm 0.3, P<0.05)$ upon resveratrol $(100 \mathrm{mg} / \mathrm{kg})$ treatment compared to $\mathrm{CCl}_{4}$ control (Figure 7(c)). A more decrement of IL-6 immunopositivity was observed $(8.2 \pm 0.6, P<0.01)$ in resveratrol- $(200 \mathrm{mg} / \mathrm{kg})$ treated rats compared to $\mathrm{CCl}_{4}$ control (Figure $7(\mathrm{~d})$ ).

2.7. Estimation of TNF- $\alpha$ and IL-6 by ELISA. Levels of cytokines (TNF- $\alpha$ and IL-6) in liver homogenate were shown in Figure 8. The levels of TNF- $\alpha$ (Figure 8(a)) and IL-6 (Figure 8(b)) were significantly $(P<0.01)$ elevated in $\mathrm{CCl}_{4}$ control group. Treatment with resveratrol at the dose 100 and $200 \mathrm{mg} / \mathrm{kg}$ significantly $(P<0.01)$ reduced the level of inflammatory cytokines. In addition with these, the effect of resveratrol at $200 \mathrm{mg} / \mathrm{kg}$ was found more significant $(P<0.01)$ when compared to resveratrol- $100 \mathrm{mg} / \mathrm{kg}$-treated group.

2.8. Effect of Resveratrol on Apoptosis. The $\mathrm{CCl}_{4}$ injection caused necrosis along with apoptosis in a dose- and duration dependent-manner in experimental animal models. The immunohistochemical analysis of apoptosis was performed by TUNEL method (Figure 9). The chromogen-generated 
TABLE 3: Effect of resveratrol on the size distribution and growth of hepatocyte nodules induced by $\mathrm{CCl}_{4}$ in rats.

\begin{tabular}{|c|c|c|c|c|c|}
\hline \multirow{2}{*}{ Groups } & \multirow{2}{*}{ No. of rats with nodules } & \multicolumn{2}{|c|}{ Nodules relative to size ( $\%$ of total no.) } & \multirow{2}{*}{ Mean nodular volume $\left(\mathrm{cm}^{3}\right)$} & \multirow{2}{*}{$\begin{array}{l}\text { Nodular volume/liver } \\
\text { volume }(\%)\end{array}$} \\
\hline & & $<3->1 \mathrm{~mm}$ & $<1 \mathrm{~mm}$ & & \\
\hline B & 10 & $59 \pm 7$ & $41 \pm 14$ & $0.17 \pm 0.04$ & $1.3 \pm 0.34$ \\
\hline $\mathrm{C}$ & 6 & $49 \pm 15$ & $51 \pm 12$ & $0.06 \pm 0.02^{*}$ & $0.49 \pm 0.14^{*}$ \\
\hline $\mathrm{D}$ & 3 & $31 \pm 12$ & $69 \pm 7$ & $0.03 \pm 0.05^{* *}$ & $0.30 \pm 0.22^{* * \#}$ \\
\hline
\end{tabular}

Group B, $\mathrm{CCl}_{4}$-administered rats; group C, resveratrol- $(100 \mathrm{mg} / \mathrm{kg})$ treated rats; group D, resveratrol- $(200 \mathrm{mg} / \mathrm{kg})$ treated rats.

Results are mean \pm S.E.M for 10 animals; One way ANOVA followed by Dunnett's multiple comparison test.

${ }^{*} P<0.05$ and ${ }^{* *} P<0.01$ as compared with group B.

${ }^{\#} P<0.05$ as compared with group $C$.

Animals from group A did not show any visible hepatocyte nodule.

TABLE 4: Effect of the resveratrol treatment $(100 \mathrm{mg} / \mathrm{kg}, 200 \mathrm{mg} / \mathrm{kg}$ body weight $)$ for 8 weeks on the lipid peroxidation, glutathione reductase, and glutathione-s-transferase in liver tissue of $\mathrm{CCl}_{4}$-induced rats.

\begin{tabular}{lccc}
\hline Group & TBARS (nmol/g liver weight) & GSH content (nmol/mg protein) & GST content (nmole/min/mg protein) \\
\hline A & $106 \pm 2.4^{* *}$ & $110 \pm 2.2^{* *}$ & $1622 \pm 3.2^{* *}$ \\
B & $303 \pm 3.2$ & $75 \pm 1.5$ & $720 \pm 2.5$ \\
C & $210 \pm 3.5^{*}$ & $90 \pm 2.2^{*}$ & $1145 \pm 2.4^{*}$ \\
D & $129 \pm 2.7^{* * *}$ & $107 \pm 1.2^{* * \#}$ & $1543 \pm 3.6^{* * *}$ \\
\hline
\end{tabular}

Group A, normal control; group B, $\mathrm{CCl}_{4}$-administered rats; group C, resveratrol-(100 mg/kg) treated rats; group D, resveratrol-(200 mg/kg) treated rats.

Results are mean \pm S.E.M for 10 animals; One way ANOVA followed by Dunnett's multiple comparison test.

${ }^{*} P<0.05$ and ${ }^{* *} P<0.01$ as compared with group B.

${ }^{\#} P<0.05$ as compared with group $C$.

TABLE 5: The expression of TNF- $\alpha$ and IL-6 immunopositive cells of the $\mathrm{CCl}_{4}$-induced liver tissue after 8 weeks of resveratrol treatment.

\begin{tabular}{lcc}
\hline Groups & TNF- $\alpha(\%)$ & IL-6 (\%) \\
\hline B & $28.5 \pm 2.4$ & $18.2 \pm 0.7$ \\
C & $15.3 \pm 3.6^{*}$ & $12.4 \pm 0.3^{*}$ \\
D & $10.6 \pm 4.7^{* *}$ & $8.2 \pm 0.6^{* *}$ \\
\hline
\end{tabular}

The expression of TNF- $\alpha$, IL- 6 was not detectable in livers of normal control group rats.

Approximately, 200 cells were counted per field, five fields were examined per slide, and five slides were examined per group.

Values are presented as mean \pm S.E.M and results were analyzed by One way ANOVA confirmed by Dunnett's test as appropriate using graph pad prism. ${ }^{*} P<0.05$ and ${ }^{* *} P<0.01$ as compared with Group B.

brown stain is an indication of apoptotic cells. It should be noted that in almost every case, the brown stain overlaps the condensed chromatin of apoptotic bodies, thus confirming that the TUNEL assay correlates well with the morphological appearance of apoptosis. The rate of apoptosis was generally very low in normal control group (Figure 9(a)), and more positive staining was expressed in $\mathrm{CCl}_{4}$-induced liver sections (Figure 9(b)). Less apoptotic cells were observed in resveratrol-treated groups (group C and D) (Figures 9(c) and 9(d)). The percentage of TUNEL positive apoptotic cells was denoted as apoptotic index. The apoptotic index value of group B was found as $21.3 \pm 1.2$. Reduction of apoptosis $(13.71 \pm 0.17)$ by resveratrol $(100 \mathrm{mg} / \mathrm{kg})$ was statistically significant $(P<0.05)$ as compared to group B. Furthermore, the reduction of apoptosis $(10.6 \pm 0.28)$ in high dose of resveratrol $(200 \mathrm{mg} / \mathrm{kg})$ was more statistically significant $(P<0.01)$ when compared to $\mathrm{CCl}_{4}$ control group.
The apoptotic index value of group D was significantly less $(P<0.05)$ as compared to group $\mathrm{C}$.

\section{Discussion}

The antioxidant and free radical scavenging activities of many substances have been assessed, and reports suggested that compounds having strong antioxidant activity showed promising hepatoprotective activity [30, 31]. Polyphenolic compounds, which are widely distributed in fruits, are considered to play an important role as dietary antioxidants for the prevention of oxidative damage during pathogenesis [32]. Therefore, we hypothesized that resveratrol, a polyphenolic compound, would be beneficial in the prevention of various liver injuries induced by oxidative stress.

Liver injury induced by $\mathrm{CCl}_{4}$ is the best characterized system of xenobiotic induced hepatotoxicity and is a commonly used model for screening hepatoprotective drugs [33-35]. Earlier studies described the effect of resveratrol on acute liver damage induced by high dose of $\mathrm{CCl}_{4}$ [36]. Resveratrol was found to prevent fibrosis by reduction of NF-kappa $\beta$ activation and TGF- $\beta$ content in $\mathrm{CCl}_{4}$ induced liver damage in rats [37]. Our data first indicates that subchronic $\mathrm{CCl}_{4}$ treatment provoked a clear toxicity in rats, as assessed by morphological variations reflected by markedly increased and localized in hepatic nodules, alteration of oxidative status and histopathological architecture of hepatic tissue, and overexpression of proinflammatory cytokines. Till now, the chemopreventive studies of resveratrol against $\mathrm{CCl}_{4}$ induced subchronic toxicity and its relation with apoptosis and levels of inflammatory cytokines have not been reported. In present study it has been recognized that CCl4-induced 


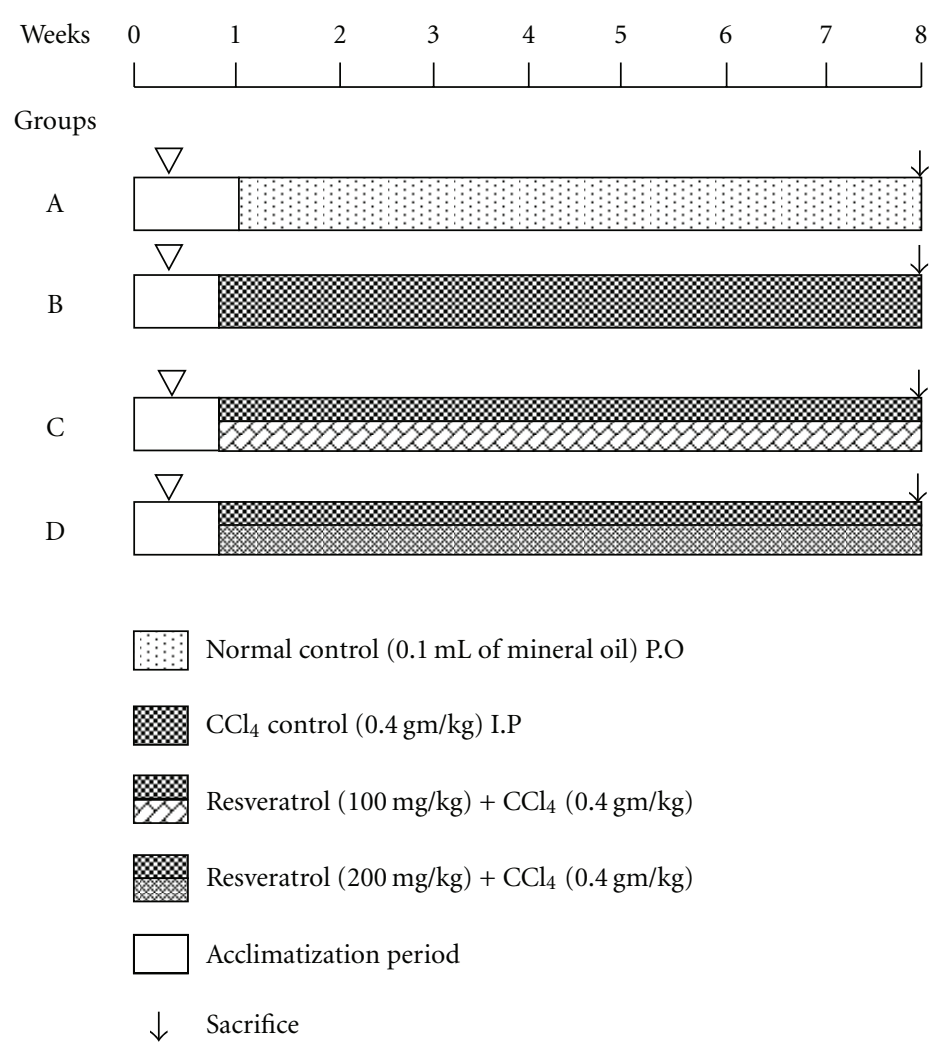

Figure 2: Schematic representation of experimental regimen.

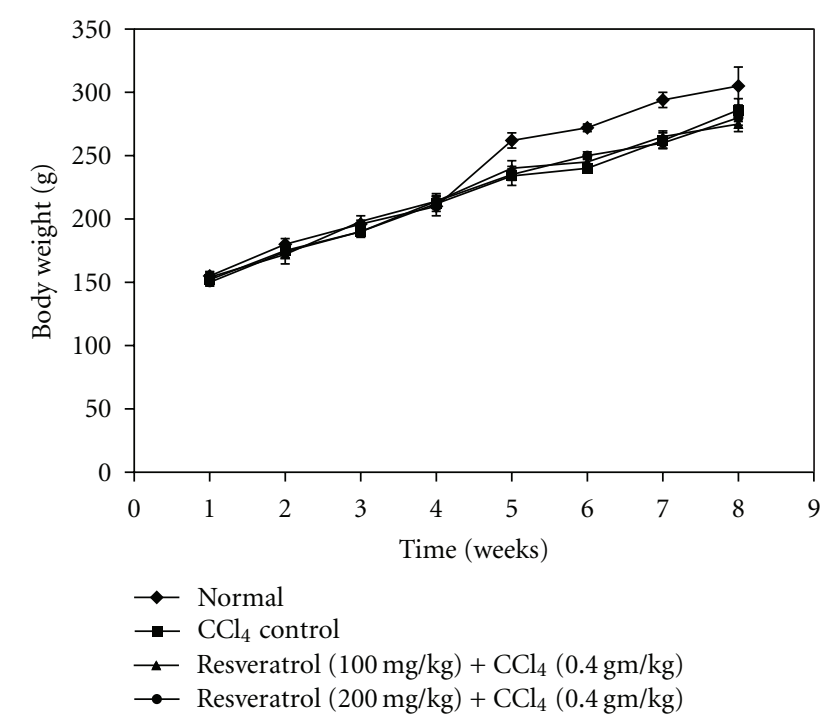

FIGURE 3: Effect of resveratrol on body weight gain during hepatic damage in rats. No significant difference in body weight was detected among the four groups.

hepatotoxicity is mediated through an apoptotic mode of action of hepatocytes secondary to the cytolethality. Resveratrol appears as a good candidate in the prevention of CCl4induced rat liver injury. In our present study, the body weight of experimental animals was not altered, and this may be considered to be an important aspect of resveratrol action.

The findings of the present investigation demonstrated that resveratrol treatment greatly reduced $\mathrm{CCl}_{4}$-initiated hepatic damage in rats, and administration of resveratrol by oral route ameliorates nodule formation. Even though during the life span of animals not all the hepatocyte nodules become malignant but numerous studies support that the neoplastic/hyperplastic nodules are the precursors of hepatic cancer. In present study, the effect of resveratrol on inhibition of nodule growth and enhancement of their regression was observed.

Previous studies suggested that GSH plays a key role in detoxifying the reactive toxic metabolites of $\mathrm{CCl}_{4}$. Failure to detoxify the metabolites promotes liver necrosis $[38,39]$. GSH form adducts with the toxic metabolites of $\mathrm{CCl}_{4}$ and contributes to the detoxification of $\mathrm{CCl}_{4}$. It has been suggested that one of the principal causes of $\mathrm{CCl}_{4}$-induced liver injury is lipid peroxidation caused by its free radical derivatives [38]. GST is a soluble protein located in the cytosol that plays an important role in the detoxification and excretion of xenobiotics [40]. Moreover, GST functionally binds with GSH and endogenous and exogenous substances. Our findings showed that treatment with resveratrol significantly inhibited lipid peroxidation, reduced $\mathrm{CCl}_{4}$-induced hepatic GSH depletion, and enhanced the GST activity.

Histological findings clearly showed that the normal architecture of the hepatic tissue was altered due to administration of $\mathrm{CCl}_{4}$-released reactive oxygen species causing 


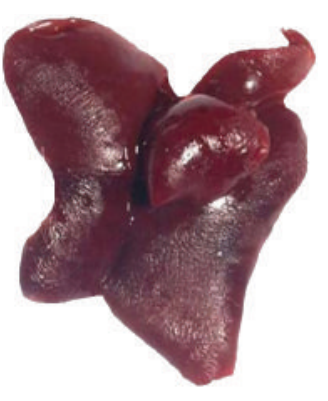

(a)

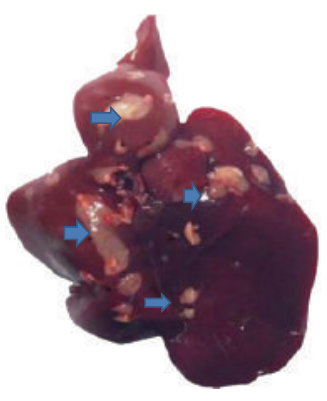

(b)

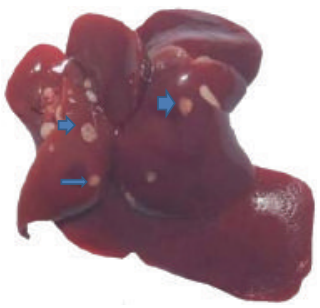

(c)

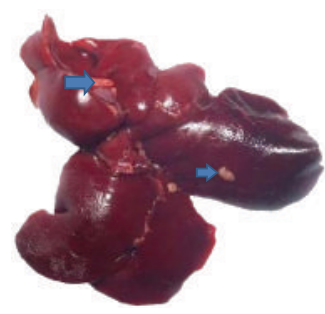

(d)

Figure 4: Morphological examination of rat liver tissue at the end of the study. Macroscopically visible hepatic nodules were shown by arrows. Representative livers are taken from several groups: (a) Normal control (group A); (b) $\mathrm{CCl}_{4}$ control (group B); (c) Resveratrol $100 \mathrm{mg} / \mathrm{kg}+\mathrm{CCl}_{4}(0.4 \mathrm{~g} / \mathrm{kg})\left(\right.$ group C); (d) Resveratrol $200 \mathrm{mg} / \mathrm{kg}+\mathrm{CCl}_{4}(0.4 \mathrm{~g} / \mathrm{kg})($ group D)

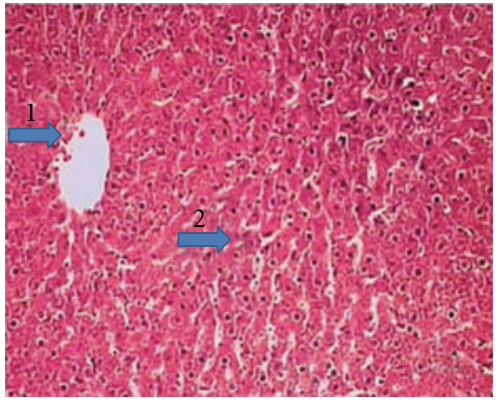

(a)

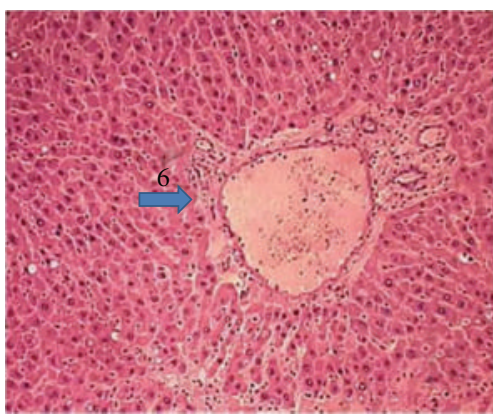

(c)

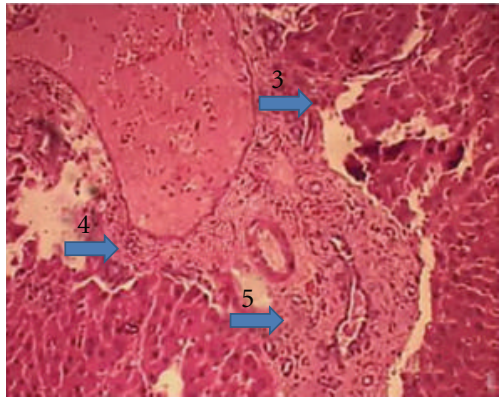

(b)

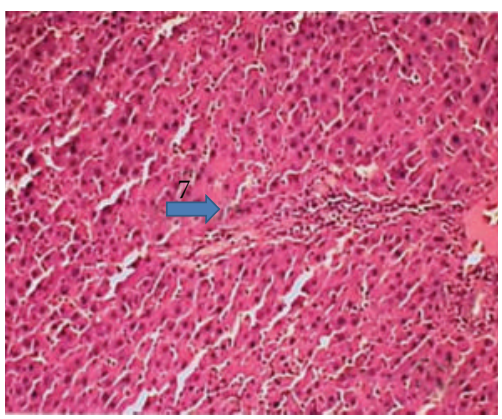

(d)

FIGURE 5: Histological profile of representative liver tissue in experimental animals. (a) Normal control rat liver (group A). Arrow 1 indicates the normal structure of central vein with radially arranged hepatocytes around it. Arrow 2 indicates normal hepatocytes (H \& E X 200); (b) $\mathrm{CCl}_{4}$ control (group B). Arrow 3 showed dilation of the central vein with few regenerative areas of hepatocytes around the central vein and distal part of liver. 4, 5 arrow showed extensive centrilobular necrosis around the central vein of liver (H \& E X 200); (c) section from resveratrol $(100 \mathrm{mg} / \mathrm{kg})+\mathrm{CCl}_{4}$ (group C) arrow 6 represents the magnitude of dilation of the central vein (H \& E X 200); (d) section from resveratrol $(200 \mathrm{mg} / \mathrm{kg})+\mathrm{CCl}_{4}($ group D) arrow 7 showed good protection of hepatocellular necrosis with a poorly dilated central vein and regular arrangement of hepatocytes around the central vein and also the distal part of the liver from the central vein along with a scattered regenerative zone of hepatocytes; very few necrotic zones were prominent showing hepatocytes maintaining nearnormal architecture ( $\mathrm{H} \&$ E X 200).

degeneration in hepatocytes, extensive centrilobular necrosis around the central vein of liver. In contrast, rats treated with resveratrol showed noticeable improvement in histopathological parameters. There was no sign of necrotic region and dilation of central vein. Our result is also at per of recent findings that resveratrol protects primary rat hepatocytes against cell damage induced by reactive oxygen species [41].
In this study, we analyzed the inhibitory effect of resveratrol on the release of proinflammatory cytokines in $\mathrm{CCl}_{4}-$ induced rat hepatic damage model. Cytokines serve as central regulators controlling genes, responsible for either inducing apoptosis or protective action on cell by stimulating proliferation of hepatocyte. Cytokines constitute a complex network involved in the regulation of inflammatory responses and 


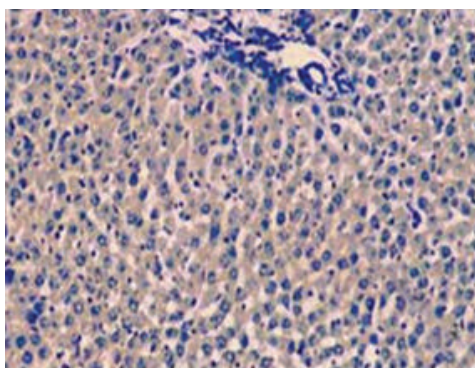

(a)

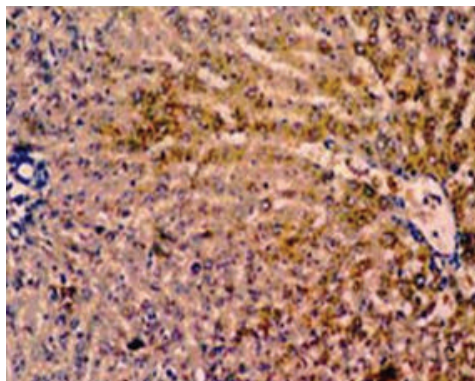

(c)

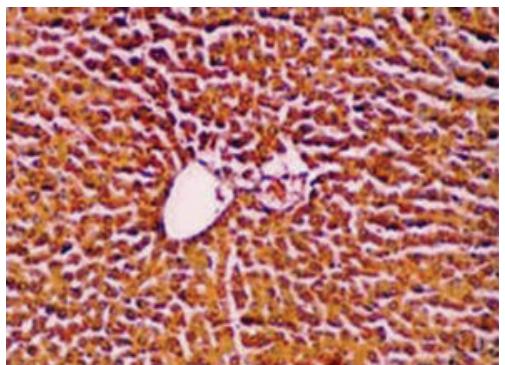

(b)

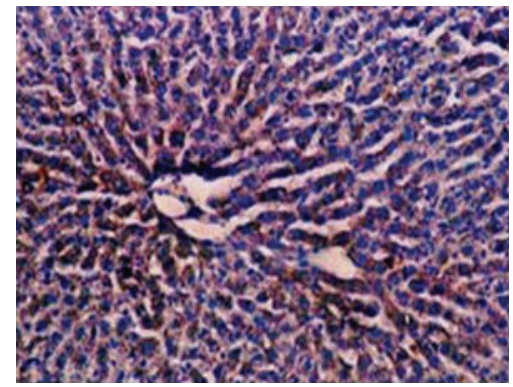

(d)

Figure 6: Immunohistochemical localisation of TNF- $\alpha$ in the rat liver tissue (H \& E X 100). The figure shows representative staining for

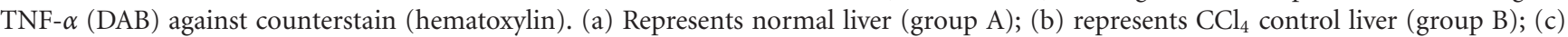
represents resveratrol $(100 \mathrm{mg} / \mathrm{kg})+\mathrm{CCl}_{4}$ (group C); (d) represents section from resveratrol $(200 \mathrm{mg} / \mathrm{kg})+\mathrm{CCl} 4$ (group D). The liver sections of control animals are mainly negative. Liver sections of $\mathrm{CCl}_{4}$-exposed rats show more intensive staining.

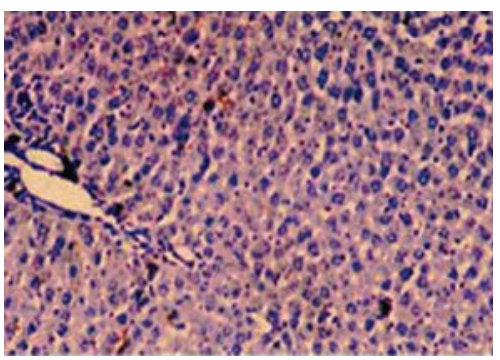

(a)

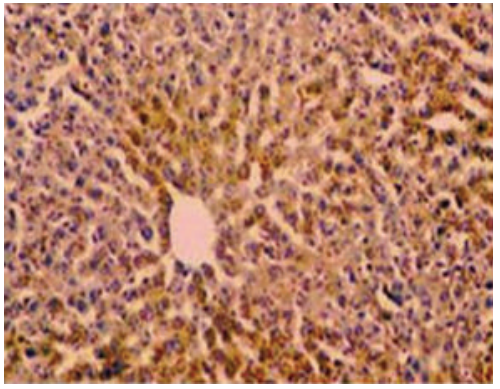

(c)

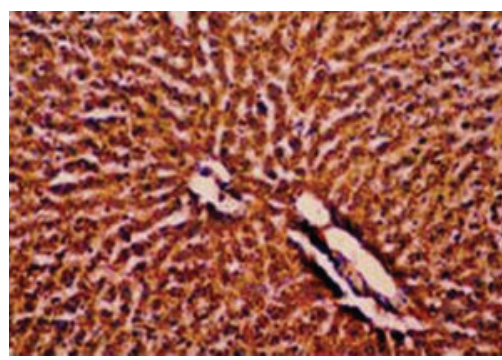

(b)

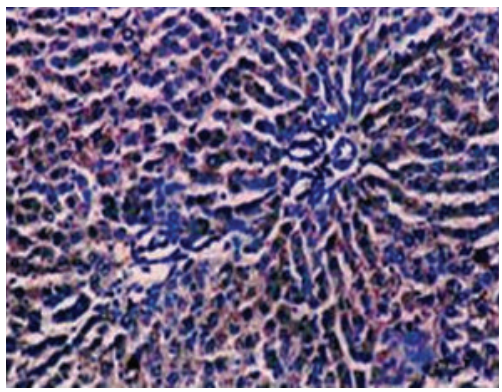

(d)

FIgURE 7: Immunohistochemical localisation of IL-6 in the rat liver tissue (H \& E X 100). The figure shows representative staining for TNF- $\alpha$ (DAB) against counterstain (hematoxylin). (a) Represents normal liver (group A); (b) represents $\mathrm{CCl}_{4}$ control liver (group B); (c) represents resveratrol $(100 \mathrm{mg} / \mathrm{kg})+\mathrm{CCl}_{4}$ (group C); (d) represents section from resveratrol $(200 \mathrm{mg} / \mathrm{kg})+\mathrm{CCl}_{4}$ (group D). The liver sections of control animals are mainly negative. Liver sections of $\mathrm{CCl}_{4}$ exposed rats show more intensive staining. 


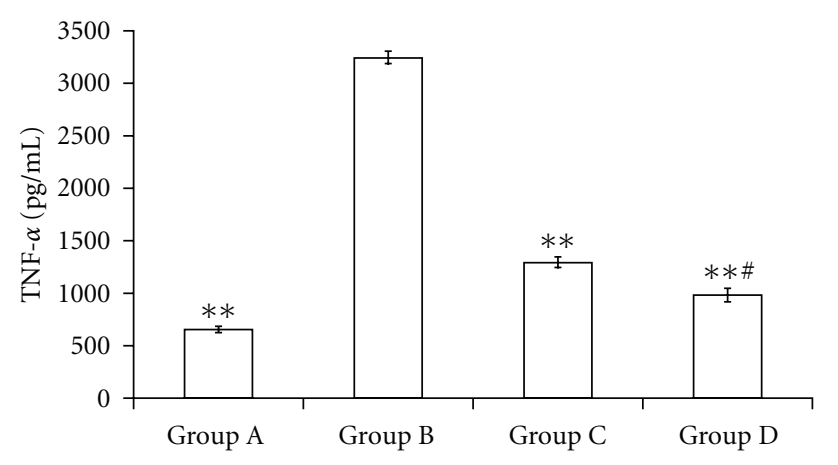

(a)

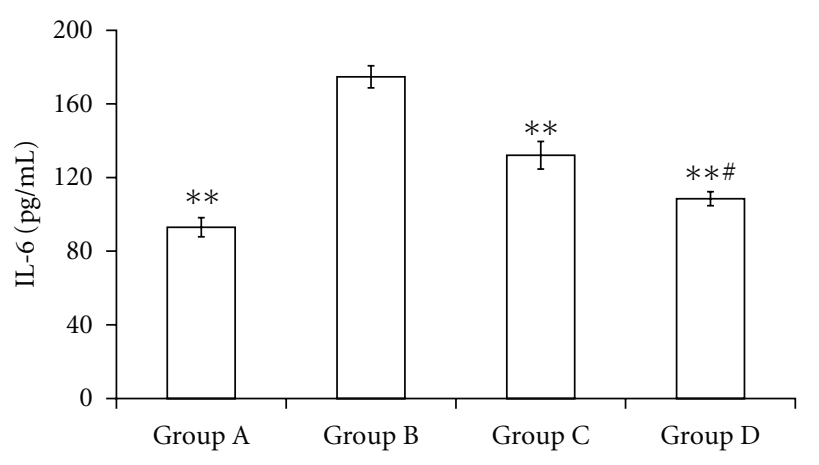

(b)

FIGURE 8: Levels of inflammatory cytokines TNF- $\alpha$ (a), and IL-6 (b) by ELISA in liver homogenate. Group A-Normal control; Group B$\mathrm{CCl}_{4}$ control; Group C—resveratrol $(100 \mathrm{mg} / \mathrm{kg})+\mathrm{CCl}_{4}$; Group D—resveratrol $(200 \mathrm{mg} / \mathrm{kg})+\mathrm{CCl}_{4}$. The values are expressed as mean \pm $\operatorname{SEM}(n=10) ;{ }^{*} P<0.01$ as compared with Group $\mathrm{B} ;{ }^{*} P<0.01$ as compared to group C.

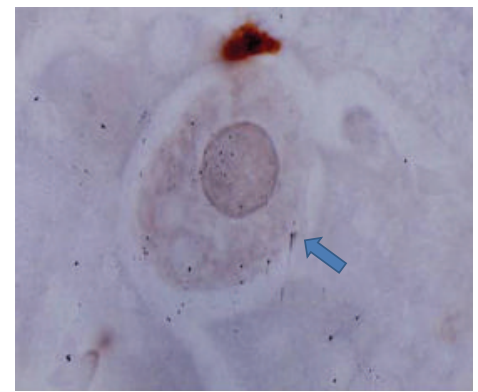

(a)

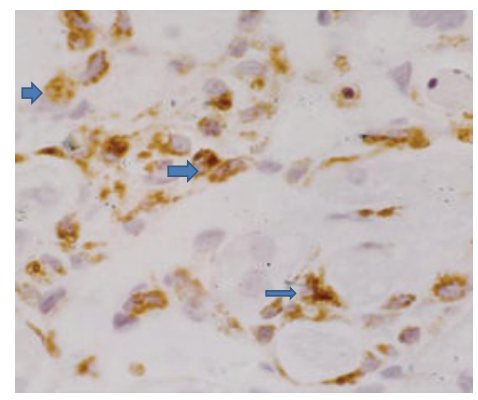

(c)

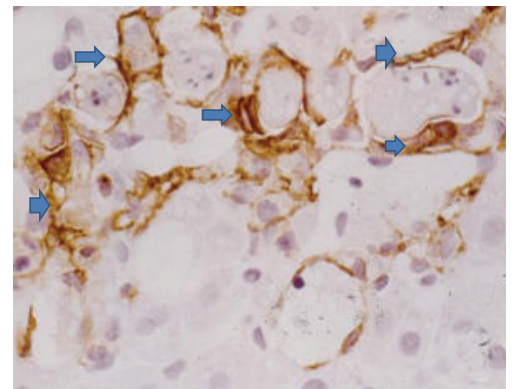

(b)

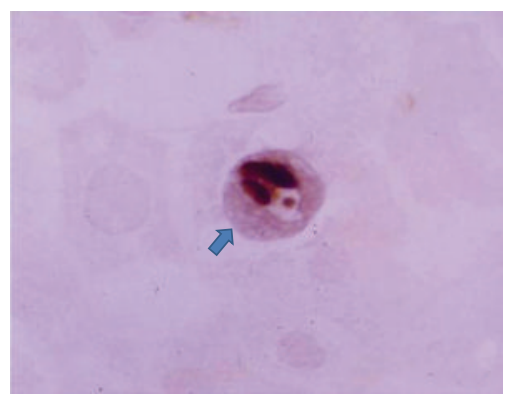

(d)

Figure 9: Apoptotic assay was performed by using TUNEL assay (H.E. X 400); brown stained cells (indicated by arrows) are undergoing apoptosis. (a) Immunostaining of rat liver from normal control (group A) showed absent of brown staining, (b) CCl $\mathrm{Control}_{4}$ (group B) liver showing more staining indicative cells undergoing apoptosis; (c) resveratrol $\left(100 \mathrm{mg} / \mathrm{kg}\right.$ ) $+\mathrm{CCl}_{4}$ (group C) exhibited less cells undergoing apoptosis; (d) resveratrol $(200 \mathrm{mg} / \mathrm{kg})+\mathrm{CCl}_{4}$ (group D) exhibited very few number of brown-stained nuclei.

maintain homeostasis of organ functions. Major hepatotoxic mediators in several experimental models of liver injury are TNF- $\alpha$ and IL-6. TNF- $\alpha$ is a circulating factor which causes necrosis of tumors when administered to tumorbearing mice. These levels are elevated in both infiltrating inflammatory cells and hepatocytes in chronic liver injuries including viral or alcoholic liver diseases, hepatitis, ischemia, and biliary obstruction [42]. Exposure to hepatotoxic chemicals facilitates TNF- $\alpha$ to induce necrotic cell death and hepatic apoptosis [43]. IL-6 is a multifunctional cytokine along with TNF- $\alpha$ activates hepatic stellate cells and increases the production of extracellular matrix proteins that finally leads to cirrhosis. Elevation of IL-6 concentration after hepatic injury suggested a potential role of IL-6 in hepatocyte proliferation, but some studies demonstrated that hepatocyte regeneration was impaired in IL-6 deficient mice [44]. In our recent findings, overexpression of TNF- $\alpha$ and IL- 6 in $\mathrm{CCl}_{4}$ control rats was markedly reduced by resveratrol-treated groups.

It was well documented that necrosis in the centrilobular zone is beloved to the injury of hepatocytes. However both necrosis and apoptosis can be caused by drugs and chemicals. 
It was studied that apoptosis is preprogrammed form of cell death which is characterized by organized cellular fragmentation; remnants resulting from this structured decay, termed apoptotic bodies, are then cleared by phagocytosis. Pathological rates of unregulated apoptosis associated with an enhanced inflammatory response and fibrosis. We investigated the possible role of apoptosis in the carbon tetrachloride-induced liver injury and its relation with chemopreventive nature of resveratrol. Our results indicate that cell loss by apoptosis occurred profoundly and rapidly in the carbon tetrachloride-challenged liver and expressed more number of TUNEL positive cells. Suppression of apoptotic incident was observed by resveratrol-treated groups.

In conclusion the protective effect of resveratrol was confirmed in a well-defined rat model of carbon tetrachlorideinduced liver injury. Recently much attention is focused on the protective functions of naturally occurring antioxidants in biological systems and their mechanisms. This study provides biological evidence that supports the use of resveratrol in the treatment of liver disorder. Downregulation of apoptosis and suppression of inflammatory cytokines levels can be attributed to molecular mechanism of hepatoprotective activity of resveratrol. Considerable efforts are being undertaken to develop specific and safe biological and molecular inhibitors of TNF- $\alpha$ and IL- 6 for potential therapeutic use. The understanding of the molecular basis for inflammatory diseases to improve human health risk assessment and also identification of functional polymorphisms for inflammatory mediators should allow for a better estimation of determining susceptible populations and help to improve human risk assessment.

\section{Materials and Methods}

4.1. Chemicals. Resveratrol, carbon tetrachloride $\left(\mathrm{CCl}_{4}\right)$, thiobarbituric acid reagent (TBA), reduced glutathione (GSH), biotinylated rabbit anti-mouse IgG, streptavidin peroxidase, antidigoxigenin peroxidase, 3,3 diaminobenzidine tetrahydro chloride (DAB), terminal deoxynucleotidyl transferase (TdT), and deoxyuridine triphosphate (dUTP) were obtained from Sigma Chemical Company (St. Louis, Mo, USA). ELISA kit was purchased from BD Bioscience (San Jose, Calif, USA). Glutathione-S-transferase detection kit was purchased from Stratagene (La jolla, Calif, USA). The rabbit anti-mouse TNF- $\alpha$ and IL- 6 antibody procured from Anaspec Inc. (San Jose, Calif, USA). All other chemicals and reagents were used of analytical grade purchased purest form available from local firms.

4.2. Animals and Diet. Pathogen-free male Wistar rats, initially weighing $100-150 \mathrm{~g}$, were obtained from Indian Institute of Chemical Biology (IICB, Kolkata, India). The animals were acclimatized to standard laboratory conditions (temperature $18 \mathrm{C} \pm 2 \mathrm{C}$, relative humidity $40 \%$ to $70 \%$ and a $12 \mathrm{~h}: 12 \mathrm{~h}$ light/dark cycle) and housed in solid bottom polypropylene cages (four animals per cage) bedding for one week before starting the experiment. The animals were fed with a semipurified basal diet and demineralized drinking water ad libitum. The recommendations of "Institutional Animal Ethical Committee" [Committee for the Purpose of Control and Supervision of Experiments on Animals (CPCSEA Regn. no. 1126/bc/07CPCSEA) India] for the care and use of laboratory animals were strictly followed throughout the experiment.

4.3. Induction of Hepatic Injury. The experimental hepatic injury was initiated by intraperitoneal injection of carbon tetrachloride $(0.4 \mathrm{~g} / \mathrm{kg} /$ day $)$ dissolved in purified mineral oil and continued up to 8 weeks. It is an important xenobiotic swallowing or inhalation exposure of $\mathrm{CCl}_{4}$ over a period of time which increases the frequency of liver damage in animals [45].

4.4. Resveratrol Dose Selection. The doses of resveratrol $100 \mathrm{mg}$ and $200 \mathrm{mg} / \mathrm{kg}$ bodyweight/day were selected based on previously reported chemopreventive and toxicological properties of this compound in rats. These doses have been found to suppress diethyl nitrosamine-initiated hepatocarcinogenesis in rodent model [46]. Resveratrol is not soluble in water therefore administered by suspended in $0.7 \%$ of carboxymethyl cellulose.

4.5. Experimental Design. After acclimatization, rats were divided randomly into four groups with ten animals each (Figure 2). Normal control (group A) was treated with $0.1 \mathrm{~mL}$ of mineral oil and $\mathrm{CCl}_{4}$ control (group B) was treated with $\mathrm{CCl}_{4}(0.4 \mathrm{~g} / \mathrm{kg} /$ day). Treatment group (group C) animals received resveratrol at a concentration of $100 \mathrm{mg} / \mathrm{kg}$ orally along with $\mathrm{CCl}_{4}(0.4 \mathrm{~g} / \mathrm{kg} /$ day $)$ and continued up to 8 weeks. Another group (group D) was treated with resveratrol at a concentration of $200 \mathrm{mg} / \mathrm{kg}$ orally along with $\mathrm{CCl}_{4}$ $(0.4 \mathrm{~g} / \mathrm{kg} /$ day $)$ and continued up to 8 weeks. Body weights of animals were recorded every one week. After 8 weeks, animals were kept for overnight fasting and sacrificed randomly. Liver sections were collected and used for further experiment.

4.6. Morphology. Animals from each group were sacrificed with ether anesthesia. The livers were quickly excised, rinsed with ice-cold phosphate-buffered saline $(\mathrm{pH}$ 7.4) to flush out any blood, blotted dry on a paper towel, weighed, and photographed. Each liver was examined macroscopically on the surface as well as in $3 \mathrm{~mm}$ cross-sections for gross visible hepatocyte nodules from all groups of the rats. The nodules were measured with a vernier caliper through its two perpendicular planes to the nearest $\mathrm{mm}$ to obtain an average diameter of each nodule. The nodules were counted and categorized into two groups according to their respective diameters $(<3->1$ and $<1 \mathrm{~mm})$. Nodular volume $(V)$ was determined by using the formula

$$
V=\frac{4}{3} \pi r^{3},
$$

where $r=$ half of the average diameter (mm). 
TABLE 6: Quantification of hepatic apoptosis of rats at the end of the study.

\begin{tabular}{lc}
\hline Groups & Apoptotic index $^{\mathrm{a}}(\mathrm{AI})$ \\
\hline B & $21.3 \pm 1.2$ \\
C & $13.71 \pm 0.17^{*}$ \\
D & $10.60 \pm 0.28^{* *}$ \\
\hline
\end{tabular}

Group B, $\mathrm{CCl}_{4}$-administered rats; group C, resveratrol- $(100 \mathrm{mg} / \mathrm{kg})$ treated rats; group D, resveratrol- $(200 \mathrm{mg} / \mathrm{kg})$ treated rats. Results are mean \pm S.E.M for 10 animals; One way ANOVA followed by Dunnett's multiple comparison test.

${ }^{*} P<0.05$ and ${ }^{*}{ }^{*} P<0.01$ as compared to group B.

Approximately 200 cells were counted per field, five fields were examined per slide, and five slides were examined per group.

${ }^{a}$ The percentage of TUNEL positive apoptotic cells was denoted as apoptotic index $(\mathrm{AI})$.

4.7. Assessment of Lipid Peroxidation. Hepatic lipid peroxidation levels were determined by measuring thiobarbituric acid-reactive substance (TBARS) [47]. Samples were mixed with thiobarbituric acid (TBA) reagent consisting of $0.375 \%$ TBA and $15 \%$ trichloroacetic acid in $0.25 \mathrm{~N}$ hydrochloric acid. The reaction mixtures were placed in a boiling water bath for $30 \mathrm{~min}$. The samples were centrifuged $(2000 \mathrm{rpm}$ for $10 \mathrm{~min}$ at $48^{\circ} \mathrm{C}$ ), and the TBARS concentration was determined based on the absorbance at $532 \mathrm{~nm}$ measured with a spectrophotometer at room temperature.

4.8. Hepatic GSH and GST Activity. Livers were quickly removed and weighed and perfused with ice-cold $0.15 \mathrm{M}$ $\mathrm{KCl}$ and then homogenized with 4 volumes of $10 \mathrm{mM}$ tris$\mathrm{HCl}$ (pH 7.4) containing 0.15 M KCl, 0.1 mM EDTA, $1.0 \mathrm{mM}$ dithiothreitol, and $0.01 \mathrm{mM}$ phenylmethylsulfonyl fluoride in an Ultra Turrax tissue homogenizer. Hepatic GSH levels were estimated colorimetrically (Systronic 2202, Ahmedabad, India) using Ellman's reagent [48]. Cytosolic GST activity was determined using 1-chloro-2,4-dinitrobenzene as a substrate [49].

4.9. Histopathology. Eight weeks after the $\mathrm{CCl}_{4}$ or vehicle treatment animals from each group were randomly selected; a portion of the liver was excised from ether-anaesthetized rat fixed in $10 \%$ formalin and processed for histopathological studies. The tissues were dehydrated through 70, 90, and $100 \%$ alcohol and embedded in low melting point paraffin wax. Section of $5 \mu \mathrm{M}$ thickness was cut and placed serially on glass slide. Each liver tissue was stained with hematoxylin and eosin for histopathological evaluation using light microscopy.

4.10. Immunostaining of TNF- $\alpha, I L-6$. Immunohistochemical detection of TNF- $\alpha$ and IL- 6 in cold acetone fixed, paraffin-embedded liver sections was performed by the avidin-biotin-peroxidase complex method. Briefly $5 \mu \mathrm{M}$ thin sections of lysine coated slides were deparaffinised and rehydrated. For immunolabeling of TNF- $\alpha$ and IL- 6 antigen retrieval was facilitated by heating the sections in citrate buffer $\mathrm{pH}$ 6.0, for $20 \mathrm{~min}$. Endogenous peroxidase activity was blocked with $1 \% \mathrm{H}_{2} \mathrm{O}_{2}$ in $0.1 \mathrm{M}$ Tris- $\mathrm{NaCl}$, $(\mathrm{pH} 7.6)$ for
30 min. After incubated in 5\% normal goat serum, sections were then separately incubated overnight at $4^{\circ} \mathrm{C}$ with the primary purified anti-mouse TNF- $\alpha$ antibody, primary purified anti-mouse IL- 6 antibody at $1: 50$ dilutions, respectively, in $1 \%$ bovine serum albumin (BSA). Sections were then incubated with a biotinylated secondary antibody, goat antirabbit IgG (Sigma) for $30 \mathrm{~min}$ at $37^{\circ} \mathrm{C}$ with $1: 100$ dilutions. This was followed by incubation with streptavidin peroxidase ( $1: 100$ ) for $1 \mathrm{~h}$. After that $100-400 \mu \mathrm{L}$ of diaminobenzidine tetrahydro chloride $(\mathrm{DAB})$ reagent was added to each section. As soon as sections turn brown, the slides are immersed in double-distilled water $\left(\mathrm{ddH}_{2} \mathrm{O}\right)$ two times for $5 \mathrm{~min}$ each. The sections were dehydrated and mounted with DPX and served as a positive control. The percentage of immunopositive cells was counted under a light microscope.

4.11. Enzyme-Linked Immunosorbent Assays (ELISA). Hepatic TNF- $\alpha$ and IL- 6 levels were estimated using commercial ELISA kit purchased from BD Biosciences (San Jose, Calif) as per the protocol provided by the manufacturer. Microplates were coated with $100 \mu \mathrm{L} /$ well of capture antibody and incubated overnight at $4^{\circ} \mathrm{C}$. After washes, the plates were blocked with assay diluent (BD Biosciences) at room temperature (RT) for $1 \mathrm{~h}$. One hundred microliters of liver homogenate in PBS supplemented with protease inhibitors, were added to each well of the plate, followed by incubation for $2 \mathrm{~h}$ at RT. Working detector $(100 \mu \mathrm{L})$ was loaded into each well, and the plate was incubated for an additional $1 \mathrm{~h}$ at RT before the addition of $100 \mu \mathrm{L}$ substrate solution. The reaction was stopped by adding $50 \mu \mathrm{L}$ stop solution. The absorbance was read at $450 \mathrm{~nm}$, with reference wavelength at $570 \mathrm{~nm}$ using a 96-well plate spectrometer (SpectraMax 190; Sunnyvale, Calif). Calculation of the concentrations of the cytokines was performed in a log-log linear regression according to the instructions in the protocol.

4.12. Apoptosis by TUNEL Assay. Apoptotic cells in liver tissue sections were determined by TUNEL assay. The sections were digested with proteinase $\mathrm{K}(20 \mu \mathrm{g} / \mathrm{mL}$ in PBS) for $15 \mathrm{~min}$ at room temperature and rinsed with double-distilled water. Slides were then quenched by $2 \% \mathrm{H}_{2} \mathrm{O}_{2}$ for $5 \mathrm{~min}$ at room temperature, equilibrated with buffer. Slides were then incubated with terminal deoxynucleotidyl transferase (TdT) buffer (30 mM Trizma base, pH 7.2, $140 \mathrm{mM}$ sodium cacodylate, $1 \mathrm{mM}$ cobalt chloride), followed by TdT reaction solution containing $\mathrm{TdT}$ and deoxyuridine triphosphate (dUTP) for $90 \mathrm{~min}$ at $37^{\circ} \mathrm{C}$, then washed with $2 \%$ standard saline citrate to stop the reaction for $10 \mathrm{~min}$ at room temperature. The slides were then washed with PBS for $5 \mathrm{~min}$ each and incubated with antidigoxigenin peroxidase for $30 \mathrm{~min}$ $(1: 100)$ at room temperature. Color was developed using $0.05 \%$ of diaminobenzidine tetrahydro chloride (DAB Kit Sigma, St. Louis, Mo, USA) in $0.01 \% \mathrm{H}_{2} \mathrm{O}_{2}$ diluted with tris- $\mathrm{HCl}$ ( $\mathrm{pH} 7.5)$, then lightly counterstained with leishman stain. Sections were then washed, dehydrated, and mounted. Apoptotic cells were identified by a brown stain over the nuclei. Approximately 200 cells were counted per field, five fields were examined per slide, and five slides were examined 
per group. Apoptotic index (AI) was determined as the percentage of labelled cells (TUNEL positive) with respect to the total number of cells counted using (see Table 6)

Apoptotic index (AI)

$$
=\left(\frac{\text { number of labeled cells }}{\text { total number of cells counted }}\right) \times 100 \text {. }
$$

4.13. Statistical Analysis. The data are expressed as means \pm S.E.M. Comparisons are carried out by One way ANOVA followed by posttest (Dunnett's test) as appropriate using graph pad prism. Results were considered statistically significant, when $P<0.01, P<0.05$.

\section{Acknowledgment}

The authors gratefully acknowledge Mr. Jayanta Bhowmick for his assistance in preparing and evaluating histopathological slides.

\section{References}

[1] D. Wu, Q. Zhai, and X. Shi, "Alcohol-induced oxidative stress and cell responses," Journal of Gastroenterology and Hepatology, vol. 21, no. 3, pp. S26-S29, 2006.

[2] C. Loguercio and A. Federico, "Oxidative stress in viral and alcoholic hepatitis," Free Radical Biology and Medicine, vol. 34, no. 1, pp. 1-10, 2003.

[3] I. F. Benzie, "Evolution of antioxidant defence mechanisms," European Journal of Nutrition, vol. 39, no. 2, pp. 53-61, 2000.

[4] H. Jaeschke, G. J. Gores, A. I. Cederbaum, J. A. Hinson, D. Pessayre, and J. J. Lemasters, "Mechanisms of hepatotoxicity," Toxicological Sciences, vol. 65, no. 2, pp. 166-176, 2002.

[5] G. L. Plaa and M. Charbonneau, "Detection and evaluation of chemically induced liver injury," in Principles and Methods of Toxicology, W. Hayes, Ed., pp. 1145-1178, Raven Press, New York, NY, USA, 2001.

[6] H. Tilg, "The role of cytokines in the pathophysiology of chronic liver diseases," International Journal of Clinical and Laboratory Research, vol. 23, no. 4, pp. 179-185, 1993.

[7] W. Dong, P. P. Simionova, R. Galluci et al., "Cytokine expression in hepatocytes: role of oxidant stress," Journal of Interferon \& Cytokine Research, vol. 18, pp. 629-638, 1998.

[8] D. McGregor and M. Lang, "Carbon tetrachloride: genetic effects and other modes of action," Mutation Research, vol. 366, no. 3, pp. 181-195, 1996.

[9] L. J. Zhang, J. P. Yu, D. Li, and Y. H. Huang, "Effects of cytokines on carbon tetrachloride-induced hepatic fibrogenesis in rats," World Journal of Gastroenterology, vol. 10, no. 1, pp. 77-81, 2004.

[10] K. Kovalovich, R. A. Deangelis, W. Li, E. E. Furth, G. Ciliberto, and R. Taub, "Increased toxin-induced liver injury and fibrosis in interleukin-6- deficient mice," Hepatology, vol. 31, no. 1, pp. 149-159, 2000.

[11] M. I. Luster, P. P. Simeonova, R. Gallucci, and J. Matheson, "Tumor necrosis factor $\alpha$ and toxicology," Critical Reviews in Toxicology, vol. 29, no. 5, pp. 491-511, 1999.

[12] J. K. Kundu and Y. J. Surh, "Cancer chemopreventive and therapeutic potential of resveratrol: mechanistic perspectives," Cancer Letters, vol. 269, no. 2, pp. 243-261, 2008.
[13] C. D. Venturini, S. Merlo, A. A. Souto, M. C. Fernandes, R. Gomez, and C. R. Rhoden, "Resveratrol and red wine function as antioxidants in the central nervous system without cellular proliferative effects during experimental diabetes," Oxidative Medicine and Cellular Longevity, vol. 3, no. 6, pp. 434-441, 2010.

[14] P. Kovacic and R. Somanathan, "Multifaceted approach to resveratrol bioactivity: focus on antioxidant action, cell signaling and safety," Oxidative Medicine and Cellular Longevity, vol. 3, no. 2, pp. 86-100, 2010.

[15] P. Palsamy and S. Subramanian, "Modulatory effects of resveratrol on attenuating the key enzymes activities of carbohydrate metabolism in streptozotocin-nicotinamide-induced diabetic rats," Chemico-Biological Interactions, vol. 179, no. 2-3, pp. 356-362, 2009.

[16] M. Lee, S. Kim, O. K. Kwon, S. R. Oh, H. K. Lee, and K. Ahn, "Anti-inflammatory and anti-asthmatic effects of resveratrol, a polyphenolic stilbene, in a mouse model of allergic asthma," International Immunopharmacology, vol. 9, no. 4, pp. 418-424, 2009.

[17] C. Luna, G. Li, P. B. Liton et al., "Resveratrol prevents the expression of glaucoma markers induced by chronic oxidative stress in trabecular meshwork cells," Food and Chemical Toxicology, vol. 47, no. 1, pp. 198-204, 2009.

[18] Z. D. Li, Q. Y. Ma, and C. A. Wang, "Effect of resveratrol on pancreatic oxygen free radicals in rats with severe acute pancreatitis," World Journal of Gastroenterology, vol. 12, no. 1, pp. 137-140, 2006.

[19] M. Shakibaei, C. Csaki, S. Nebrich, and A. Mobasheri, "Resveratrol suppresses interleukin- $1 \beta$-induced inflammatory signaling and apoptosis in human articular chondrocytes: potential for use as a novel nutraceutical for the treatment of osteoarthritis," Biochemical Pharmacology, vol. 76, no. 11, pp. 1426-1439, 2008.

[20] D. K. Das and N. Maulik, "Resveratrol in cardioprotection: a therapeutic promise of alternative medicine," Molecular Interventions, vol. 6, no. 1, pp. 36-47, 2006.

[21] A. K. Grissa, B. Mornagui, E. Aouani et al., "Resveratrol, a red wine polyphenol, attenuates ethanol-induced oxidative stress in rat liver," Life Sciences, vol. 80, no. 11, pp. 1033-1039, 2007.

[22] P. Cerna, D. Kotyzova, and V. Eybl, "Protective effect of resveratrol in acute liver damage in rats," Toxicology Letters, vol. 180, pp. 32-246, 2008.

[23] S. H. Khabbar, C. H. Cottart, D. Wendum et al., "Postischemic treatment by trans-resveratrol in rat liver ischemiareperfusion: a possible strategy in liver surgery," Liver Transplantation, vol. 14, no. 4, pp. 451-459, 2008.

[24] J. F. Marier, K. Chen, P. Prince, G. Scott, J. R. E. del Castillo, and P. Vachon, "Production of ex vivo lipopolysaccharideinduced tumor necrosis factor- $\alpha$, interleukin- $1 \beta$, and interleukin-6 is suppressed by trans-resveratrol in a concentrationdependent manner," Canadian Journal of Veterinary Research, vol. 69, no. 2, pp. 151-154, 2005.

[25] L. Ravagnan, T. Roumier, and G. Kroemer, "Mitochondria, the killer organelles and their weapons," Journal of Cellular Physiology, vol. 192, no. 2, pp. 131-137, 2002.

[26] J. Zhang, M. Dong, L. Li et al., "Endonuclease G is required for early embryogenesis and normal apoptosis in mice," Proceedings of the National Academy of Sciences of the United States of America, vol. 100, no. 26, pp. 15782-15787, 2003.

[27] L. Chen, Z. Yang, and F. Qiu, "Studies on hepatocyte apoptosis, proliferation and oncogene c-fos expression in carbon tetrachloride-induced cirrhotic rat liver," Journal of Tongji Medical University, vol. 19, no. 1, pp. 53-55, 1999. 
[28] M. L. Berger, H. Bhatt, B. Combes, and R. W. Estabrook, " $\mathrm{CCl}_{4}$-induced toxicity in isolated hepatocytes: the importance of direct solvent injury," Hepatology, vol. 6, no. 1, pp. 36-45, 1986.

[29] M. Leist, F. Gantner, H. Naumann et al., "Tumor necrosis factor-induced apoptosis during the poisoning of mice with hepatotoxins," Gastroenterology, vol. 112, no. 3, pp. 923-934, 1997.

[30] J. M. Hwang, T. H. Tseng, Y. S. Hsieh, F. P. Chou, C. J. Wang, and C. Y. Chu, "Inhibitory effect of atractylon on tert-butyl hydroperoxide induced DNA damage and hepatic toxicity in rat hepatocytes," Archives of Toxicology, vol. 70, no. 10, pp. 640-644, 1996.

[31] S. Luper, "A review of plants used in the treatment of liver disease: part 1," Alternative Medicine Review, vol. 3, no. 6, pp. 410-421, 1998.

[32] K. V. Pugalendi and T. Radhiga, "Potential beneficial effect of protocatechuic acid on hepatic markers, lipid peroxidation and antioxidant status against D-Galactosamine induced toxicity in rats," Pharmaceutical Research, vol. 4, pp. 222-225, 2011.

[33] J. A. Brent and B. H. Rumack, "Role of free radicals in toxic hepatic injury. II. Are free radicals the cause of toxin-induced liver injury?" Journal of Toxicology-Clinical Toxicology, vol. 31, no. 1, pp. 173-196, 1993.

[34] N. Brautbar and J. Williams, "Industrial solvents and liver toxicity: risk assessment, risk factors and mechanisms," International Journal of Hygiene and Environmental Health, vol. 205, no. 6, pp. 479-491, 2002.

[35] M. K. Manibusan, M. Odin, and D. A. Eastmond, "Postulated carbon tetrachloride mode of action: a review," Journal of Environmental Science and Health: Part C, vol. 25, pp. 185-209, 2007.

[36] H. Rivera, M. Shibayama, V. Tsutsumi, V. Perez-Alvarez, and P. Muriel, "Resveratrol and trimethylated resveratrol protect from acute liver damage induced by CCI4 in the rat," Journal of Applied Toxicology, vol. 28, no. 2, pp. 147-155, 2008.

[37] E. Chávez, K. Reyes-Gordillo, J. Segovia et al., "Resveratrol prevents fibrosis, NF- $\kappa \mathrm{B}$ activation and TGF- $\beta$ increases induced by chronic CCl4 treatment in rats," Journal of Applied Toxicology, vol. 28, no. 1, pp. 35-43, 2008.

[38] R. O. Recknagel, E. A. Glende Jr., and R. S. Briton, "Free radical damage and lipid peroxidation," in Hepatotoxicology, R. G. Meeks, Ed., pp. 401-436, CRC Press, Florida, Fla, USA, 1991.

[39] A. T. Williams and R. F. Burk, "Carbon tetrachloride hepatotoxicity: an example of free radical-mediated injury," Seminars in Liver Disease, vol. 10, no. 4, pp. 279-284, 1990.

[40] T. D. Boyer, D. A. Vessey, C. Holcomb, and N. Saley, "Studies of the relationship between the catalytic activity and binding of non-substrate ligands by the glutathione S-transferases," Biochemical Journal, vol. 217, no. 1, pp. 179-185, 1984.

[41] J. A. Rubiolo and F. V. Vega, "Resveratrol protects primary rat hepatocytes against necrosis induced by reactive oxygen species," Biomedicine and Pharmacotherapy, vol. 62, no. 9, pp. 606-612, 2008.

[42] I. Hernandez-Munoz, P. De la Torre, J. A. Sanchez-Alcazar et al., "Tumor necrosis factor $\alpha$ inhibits collagen $\alpha 1$ (I) gene expression in rat hepatic stellate cells through a G protein," Gastroenterology, vol. 113, no. 2, pp. 625-640, 1997.

[43] T. Vanden Berghe, G. Denecker, G. Brouckaert, D. Vadimovisch Krysko, K. D’Herde, and P. Vandenabeele, “More than one way to die: methods to determine TNF-induced apoptosis and necrosis," Methods in Molecular Medicine, vol. 98, pp. 101126, 2004.
[44] D. E. Cressman, L. E. Greenbaum, R. A. DeAngelis et al., "Liver failure and defective hepatocyte regeneration in interleukin6- deficient mice," Science, vol. 274, no. 5291, pp. 1379-1383, 1996.

[45] K. Tsujimura, F. Ichinose, T. Hara, K. Yamasaki, M. Otsuka, and S. Fukushima, "The inhalation exposure of carbon tetrachloride promote rat liver carcinogenesis in a medium-term liver bioassay," Toxicology Letters, vol. 176, no. 3, pp. 207-214, 2008.

[46] A. Bishayee and N. Dhir, "Resveratrol-mediated chemoprevention of diethylnitrosamine-initiated hepatocarcinogenesis: inhibition of cell proliferation and induction of apoptosis," Chemico-Biological Interactions, vol. 179, no. 2-3, pp. 131-144, 2009.

[47] K. J. Lee and H. G. Jeong, "Protective effect of Platycodi radix on carbon tetrachloride-induced hepatotoxicity," Food and Chemical Toxicology, vol. 40, no. 4, pp. 517-525, 2002.

[48] K. J. Lee, E. R. Woo, C. Y. Choi et al., "Protective effect of acteoside on carbon tetrachloride induced hepatotoxicity," Life Sciences, vol. 74, no. 8, pp. 1051-1064, 2004.

[49] W. H. Habig, M. J. Pabst, and W. B. Jakoby, "Glutathione S transferases. The first enzymatic step in mercapturic acid formation," Journal of Biological Chemistry, vol. 249, no. 22, pp. 7130-7139, 1974. 


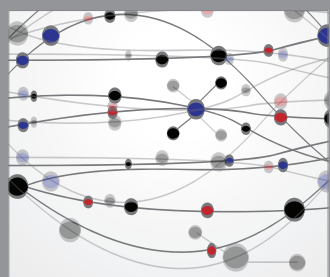

The Scientific World Journal
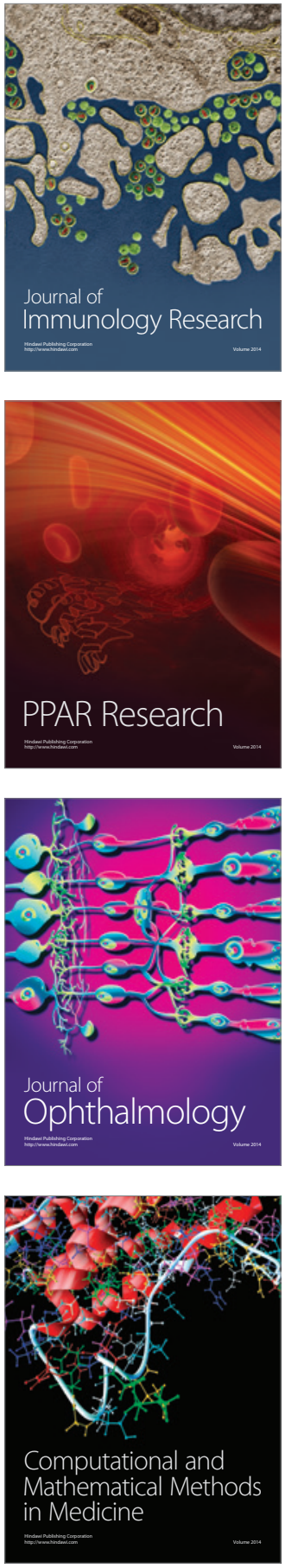

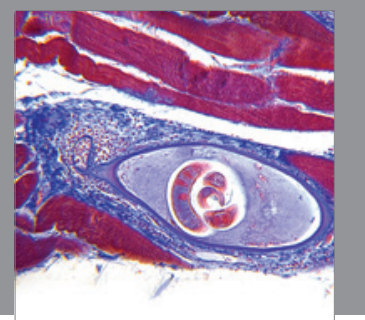

Gastroenterology

Research and Practice
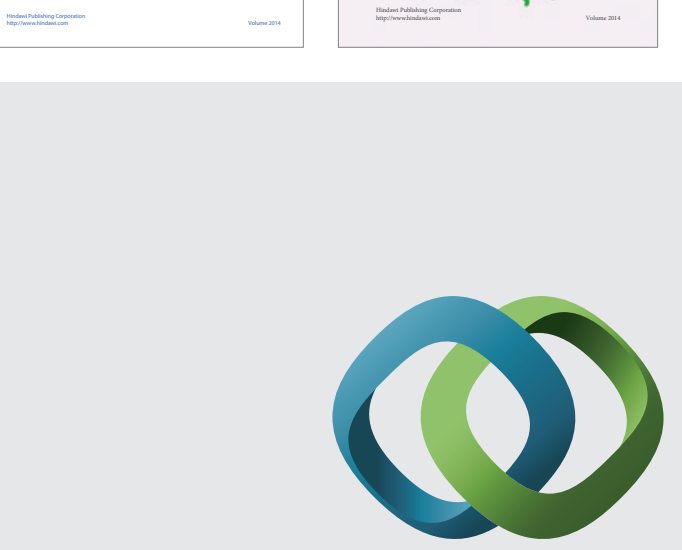

\section{Hindawi}

Submit your manuscripts at

http://www.hindawi.com
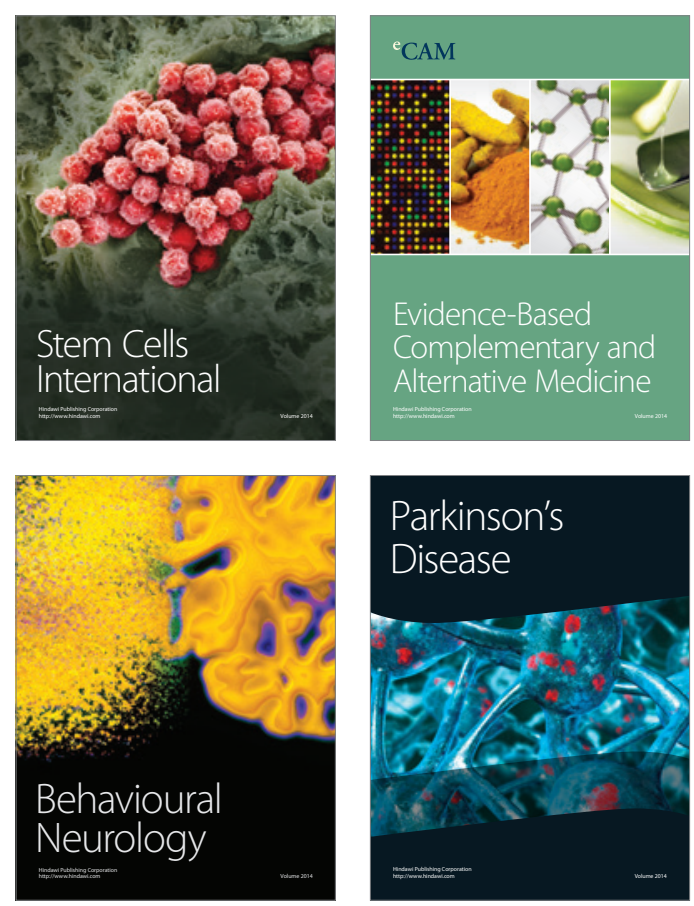

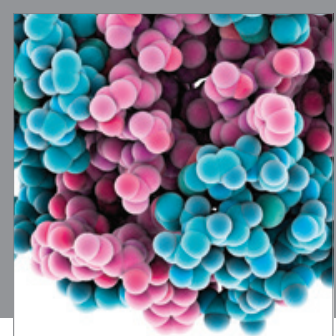

Journal of
Diabetes Research

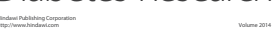

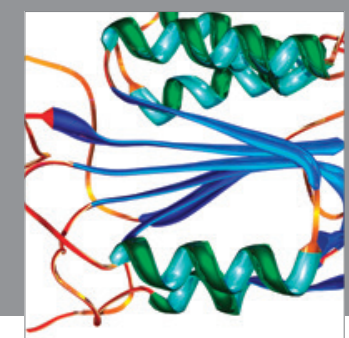

Disease Markers
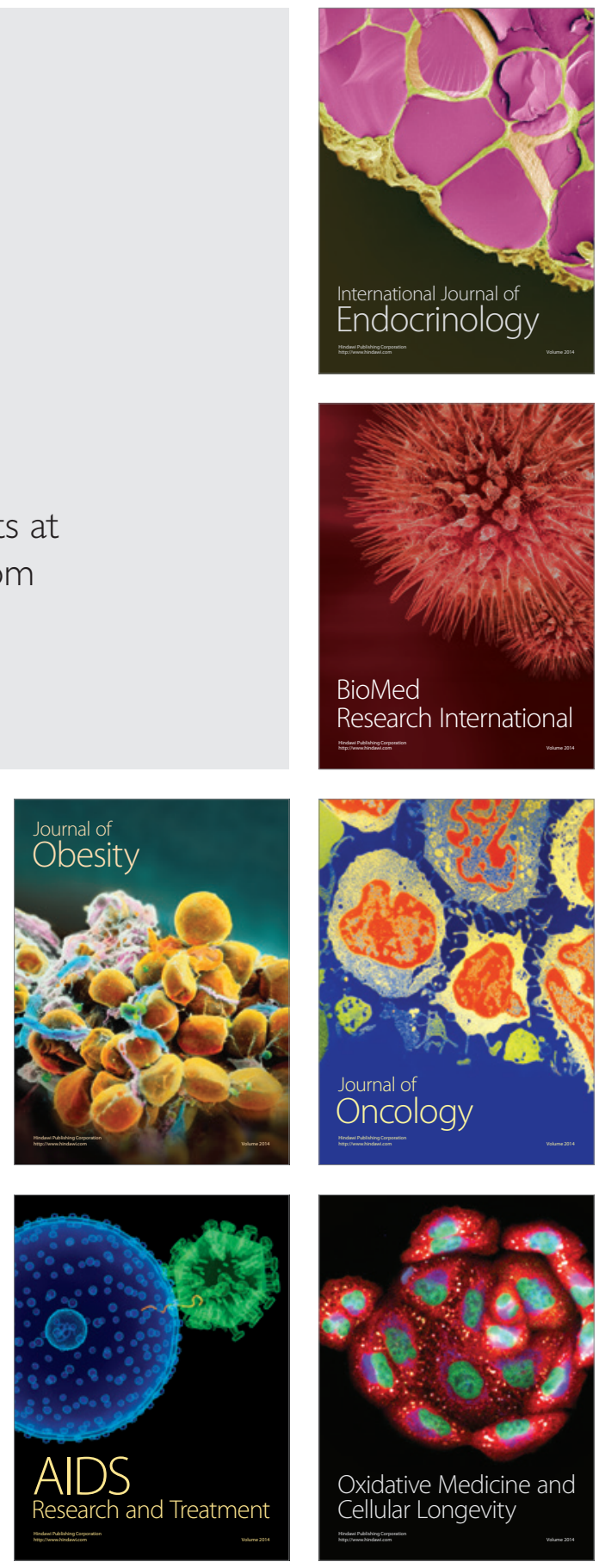